\title{
Expression, localization and synthesis of small leucine-rich proteoglycans in developing mouse molar tooth germ
}

\author{
Angammana Randilini, ${ }^{1}$ Kaoru Fujikawa, ${ }^{2}$ Shunichi Shibata1 \\ ${ }^{1}$ Department of Maxillofacial Anatomy, Graduate School of Medical and Dental Sciences, Tokyo Medical and Dental \\ University, Tokyo \\ ${ }^{2}$ Department of Oral Anatomy and Developmental Biology, Showa University School of Dentistry, Tokyo, Japan
}

The gene expression and protein synthesis of small leucine-rich proteoglycans (SLRPs), including decorin, biglycan, fibromodulin, and lumican, was analyzed in the context of the hypothesis that they are closely related to tooth formation. In situ hybridization, immunohistochemistry, and organ culture with metabolic labeling of $\left[{ }^{35} \mathrm{~S}\right]$ were carried out in mouse first molar tooth germs of different developmental stages using ICR mice at embryonic day (E) 13.5 to postnatal day (P)7.0. At the bud and cap stage, decorin mRNA was expressed only in the surrounding mesenchyme, but not within the tooth germ. Biglycan mRNA was then expressed in the condensing mesenchyme and the dental papilla of the tooth germ. At the apposition stage (late bell stage), both decorin and biglycan mRNA were expressed in odontoblasts, resulting in a switch of the pattern of expression within the different stages of odontoblast differentiation. Decorin mRNA was expressed earlier in newly differentiating odontoblasts than biglycan. With odontoblast maturation and dentin formation, decorin mRNA expression was diminished and localized to the newly differentiating odontoblasts at the cervical region. Simultaneously, biglycan mRNA took over and extended its expression throughout the new and mature odontoblasts. Both mRNAs were expressed in the dental pulp underlying the respective odontoblasts. At P7.0, both mRNAs were weakly expressed but maintained their spatial expression patterns. Immunostaining showed that biglycan was localized in the dental papillae and pulp. In addition, all four SLRPs showed clear immunostaining in predentin, although the expressions of fibromodulin and lumican mRNAs were not identified in the tooth germs examined. The organ culture data obtained supported the histological findings that biglycan is more predominant than decorin at the apposition stage. These results were used to identify biglycan as the principal molecule among the SLRPs investigated. Our findings indicate that decorin and biglycan show spatial and temporal differential expressions and play their own tissue-specific roles in tooth development.

Key words: Decorin; biglycan; tooth germ; in situ hybridization; organ culture.

Correspondence: Shunichi Shibata, Department of Maxillofacial Anatomy, Graduate School of Medical and Dental Sciences, Tokyo Medical and Dental University, 1-5-45, Yushima, Bunkyo-ku, Tokyo, 113-8549, Japan. Tel. +81.3.5803-5435 - Fax: +81.3.5803-0185. E-mail: sshibata.mfa@tmd.ac.jp

Contributions: AR, designed experimental system, performed experiments, obtained data, drafted the manuscript; KF, partially performed experiments, obtained data; SS, designed experimental system, directed total experimental system, partially performed experiments, drafted the manuscript. All the authors have read and approved the final version of the manuscript and agreed to be accountable for all aspects of the work.

Conflict of interest: The authors declare that they have no competing interests, and all authors confirm accuracy.

Availability of data and materials: The data used to support the findings of this study are available from the corresponding author upon request.

Ethics approval and consent to participate: The animal use protocol listed below has been reviewed and approved by the Institutional Animal Care and Use Committee of Tokyo Medical and Dental University (2016009A, A2017-151A, A2018-005A, and A2019-009A). 


\section{Introduction}

Small leucine-rich proteoglycans (SLRPs) have been identified as important components in the extracellular matrix (ECM) and are involved in several biological and pathological processes in various tissues. They are proteoglycans (PGs) with small core proteins of tandem leucine-rich repeats that carry one or more glycosaminoglycan (GAG) chains, such as chondroitin sulfate (CS), dermatan sulfate (DS), or keratan sulfate (KS). Eighteen SLRP genes have been identified to date and are classified into five categories based on their characteristics at both the genomic and protein levels. ${ }^{1-3}$ It has been reported that these SLRPs play significant roles in regulating the ECM by collagen formation and ECM arrangement, matrix mineralization, signal transduction, and epithelialmesenchymal interactions, as well as in immunity and tumor growth. ${ }^{4}$

The most commonly identified SLRPs in teeth are of class I and class II. ${ }^{5}$ Class I SLRPs include decorin and biglycan, which are the most studied and are relatively abundant. They are found in various tissues, such as skin, tendon, bone, cartilage, and muscle. ${ }^{6}$ They contain CS/DS chains; one in decorin and two in biglycan. Decorin plays a significant role in collagen fibrillogenesis and in preventing premature mineralization, ${ }^{7}$ whereas biglycan is more significant in osteoblast differentiation and matrix mineralization. ${ }^{8}$ In geneknockout studies, the absence of decorin gives rise to skin fragility and dysregulation of lateral fibril growth. ${ }^{9}$ Likewise, the absence of biglycan results in osteoporosis-like phenotypes. ${ }^{10}$

Class II SLRPs include fibromodulin and lumican, which are close relatives of decorin and biglycan in terms of their function. They have KS chains and are found in tissues such as tendons, cartilage, sclera, and the cornea. ${ }^{6}$ Goldberg et al. ${ }^{11,12}$ identified two different molecular weights for fibromodulin present in bone and dentin, the former of which is larger. Lumican is also involved in collagen fibrillogenesis and determines the collagen fiber diameter and spacing. ${ }^{13}$ It is also recognized as a marker for the identification of differentiating and mature osteoblasts from undifferentiated osteoblasts. ${ }^{14}$

Tooth development is a complex process regulated by epithelialmesenchymal interactions and continues through different developmental stages known as bud, cap, bell, and apposition stages. ${ }^{15}$ Throughout the tooth developmental process, the involvement of versican, a large CS- $\mathrm{PG} ;{ }^{16}$ perlecan, a large heparan sulfate (HS)-PG; ${ }^{17}$ and syndecans, small cell surface HS-PGs, ${ }^{18}$ have been thoroughly investigated. Several studies have also confirmed the involvement of SLRPs in tooth development in humans ${ }^{13,19,20}$ and other species. ${ }^{21-23}$

SLRPs have been proposed to play several roles in tooth development, including cellular differentiation, collagen fibrillogenesis, dental mineralization, and tooth eruption. ${ }^{24}$ To elucidate the exact roles of SLRPs in tooth formation, gene- knockout studies have been carried out. The absence of decorin has been found to affect dentin mineralization, whereas biglycan has been shown to have a multifunctional involvement, the knockout of which affects both amelogenesis and dentinogenesis, together with collagen fibrillogenesis in predentin. ${ }^{25}$ Fibromodulin deficiency has been found to affect enamel formation and increases the collagen diameter in predentin, as well as causing dentin hypomineralization in newborn mice, in contrast to the self-repair observed in adult mice. ${ }^{11,12}$ Lumican deficiency results in periodontal ligament phenotypes. ${ }^{26}$ Many immunohistochemical studies in tooth germs have also been performed in rodents ${ }^{21,27}$ and humans. ${ }^{13,20}$ Several in situ hybridization studies in mice have also been carried out. ${ }^{28-30}$ These studies, however, have not examined the temporal changes in SLRP expression during the process of identical tooth germ formation. Thus, our hypothesis that SLRPs are closely involved in tooth formation led us to perform an in situ hybridization study to elucidate their specific functions by investigating the formation of identical tooth germs (of the lower first molar) from the early stage to the postnatal stage. Simultaneously, the synthesis of SLRP proteins by tooth germs was investigated by immunohistochemistry and an organ culture system using metabolic labeling of $\left[{ }^{35} \mathrm{~S}\right]$.

\section{Materials and Methods}

\section{Animals}

A total of 16 pregnant Institute of Cancer Research (ICR) mice at embryonic day (E) 13.5 to E18.5 (08:00 h on the day of the vaginal plug was designated as stage E0), and a total of 12 postnatal day (P) 1.0, 3.0, and 7.0 mice were used in this study. All animals were housed in facilities approved by Tokyo Medical and Dental University. Our animal use protocol and experimental system were approved by the Institutional Animal Care and Use Committee of Tokyo Medical and Dental University (2016-009A, A2017-151A, A2018-005A, and A2019-009A).

\section{Tissue preparation}

Pregnant and postnatal mice were sacrificed by cervical dislocation under $\mathrm{CO}_{2}$ asphyxiation. The heads and lower limbs of the fetal and postnatal mice were separated and were fixed in $4 \%$ paraformaldehyde in $0.1 \mathrm{M}$ phosphate buffer, $\mathrm{pH} 7.4$ at $4^{\circ} \mathrm{C}$ for 1 day. The E18.5, P1.0, P3.0, and P7.0 specimens were decalcified in $10 \%$ ethylenediamine tetraacetic acid (EDTA) at $4^{\circ} \mathrm{C}$ for 10 days. All specimens were then embedded in paraffin. Frontal or sagittal sections of $5 \mu \mathrm{m}$ in thickness were obtained for toluidine blue (TB) general staining, immunohistochemistry, and in situ hybridization.

\section{In situ hybridization}

All primer sequences used are listed in Table 1. The cDNA

Table 1. Primer sets for RNA probes.

\begin{tabular}{|c|c|c|c|}
\hline Gene & Primer sequence $\left(5^{\prime}-3^{\prime}\right)$ & Product size & \\
\hline Decorin & $\begin{array}{l}\text { Forward: GCTCACGCAGTGAAACCTTAG } \\
\text { Reverse: CGCCCAGTTCTATGACAAGC }\end{array}$ & 754 bp & NM_001190451.2 \\
\hline Biglycan & $\begin{array}{l}\text { Forward: ATTGAGATGGGCGGGAATCC } \\
\text { Reverse: GGTTGAGGGGAATGGGTGAG }\end{array}$ & $721 \mathrm{bp}$ & NM_007542.5 \\
\hline Fibromodulin & $\begin{array}{l}\text { Forward: AGTCCACCTACTACGACCCC } \\
\text { Reverse: ACTCATTGATCCTGTTGCCC }\end{array}$ & 878 bp & NM_021355 \\
\hline Lumican & $\begin{array}{l}\text { Forward: AGTAAGGTCACAGAGGACTTGC } \\
\text { Reverse: CGAGTTTCCAGGTACCCCAC }\end{array}$ & 774 bp & NM_008524 \\
\hline
\end{tabular}


products were subcloned into a pCR II vector (Stratagene, La Jolla, CA, USA), and antisense and sense RNA probes were synthesized. Each probe was then labeled with $\left[{ }^{35} \mathrm{~S}\right]$-UTP using the Riboprobe in vitro Transcription System (Promega, Madison, WI, USA). In situ hybridization using $\left[{ }^{35} \mathrm{~S}\right]-\mathrm{UTP}$ labeled probes was performed as previously described. ${ }^{31-34}$ Following hybridization and RNase treatment, the sections were dipped in emulsion (NTB; Kodak, Rochester, NY, USA) and exposed for 2 weeks at $4^{\circ} \mathrm{C}$ for autoradiography. Sense probes were used as negative control samples. We examined three different samples for each embryonic day to ensure that consistent results were obtained.

\section{Immunohistochemistry}

Rabbit polyclonal antibodies against decorin, biglycan, and fibromodulin were obtained from Bioss Antibodies (Boston, MA, USA). A rabbit polyclonal antibody against human lumican was obtained from Funakoshi (Tokyo, Japan). Immunohistochemical staining was performed as previously described..$^{32,34,35}$ Briefly, the sections were deparaffinized and digested with testicular hyaluronidase $(25 \mathrm{mg} / \mathrm{mL}$ in phosphate buffered saline; SigmaAldrich, St. Louis, MO, USA) for $1 \mathrm{~h}$ at $37^{\circ} \mathrm{C}$. Then, the sections were immersed in methanol containing $1 \%$ hydrogen peroxide, followed by $1 \%$ bovine serum albumin to block endogenous peroxidase activity and non-specific binding, respectively. The primary antibodies diluted for decorin (1:25), biglycan (1:50), fibromodulin (1:100), and lumican (1:100) were applied and incubated overnight at $4^{\circ} \mathrm{C}$. This was followed by biotin-labelled rabbit $\operatorname{IgG}$ and peroxidase-labeled streptavidin application. 3amino-9-ethylcarbazole was used for protein visualization after counterstaining with hematoxylin. The samples were observed under a light microscope. The negative controls were incubated with normal anti-rabbit IgG instead of the primary antibodies. We examined three different samples for each embryonic day to ensure that consistent results were obtained.

\section{Organ culture and metabolic labeling with $\left[{ }^{35} \mathrm{~S}\right]$}

An organ culture system was created according to a previous study. ${ }^{16}$ Based on the results of in situ hybridization/ immunohistochemistry, we selected the lower first molar tooth germs of E16.0, E18.0, and P3.0 as representatives of the late cap stage, predentin formation stage, and enamel and dentin formation stage, respectively. A total of 36 explants of tooth germs were cultured on cell culture inserts (Millicell, Merck, Tokyo, Japan) containing BGJB medium (Gibco: Thermo Fisher Scientific, Waltham, MA, USA) supplemented with $10 \%$ fetal bovine serum (Gibco) and 1\% penicillin-streptomycin (Gibco) for $2 \mathrm{~h}$ in a humidified atmosphere of $5 \% \mathrm{CO}_{2}$ in air at $37^{\circ} \mathrm{C}$. Three tooth germs were placed on a cell culture insert. These explants were labeled with $\left[{ }^{35} \mathrm{~S}_{\mathrm{Na}_{2}} \mathrm{SO}_{4}(3.7 \mathrm{MBq} / \mathrm{mL}\right.$, American Radiolabeled Chemicals, St Louis, MO, USA) for another $12 \mathrm{~h}$ under the same culture conditions.

\section{Extraction of proteoglycan and gel filtration}

After labeling, the explants were extracted with $4 \mathrm{M}$ guanidine $\mathrm{HCl}, 50 \mathrm{mM}$ sodium acetate, $\mathrm{pH} 6.0$, containing 2\% (w/v) Triton $\mathrm{X}-100$ and $1 \%$ protease inhibitors (Sigma-Aldrich) at $4{ }^{\circ} \mathrm{C}$ for $24 \mathrm{~h}$. Each extract was subjected to a Sephadex G-50 column (Amersham Pharmacia Biotech, Tokyo, Japan) and eluted with $4 \mathrm{M}$ guanidine $\mathrm{HCl}, 50 \mathrm{mM}$ sodium acetate $(\mathrm{pH} 6.0)$ containing $0.5 \%(\mathrm{w} / \mathrm{v})$ CHAPS to remove any unincorporated radioactive precursors. The collected void volume fractions were counted with a liquid scintillation counter and estimated as the total $\left[{ }^{35} \mathrm{~S}\right]$-labeled macromolecules per dish. To assess changes of synthesized $\left[{ }^{35} \mathrm{~S}\right]-$ labeled macromolecules in amounts associated with tooth germ growth, data analyses were performed using one-way analysis of variance (ANOVA) for several group comparisons. Significance was determined using Tukey's comparison test. A P-value of $<0.05$ was considered statistically significant.

The $\left[{ }^{35} \mathrm{~S}\right]$-labeled macromolecules from the Sephadex G-50 columns were then injected into prepacked Superose 6 columns (Amersham Pharmacia Bioteck) and eluted with $4 \mathrm{M}$ guanidine $\mathrm{HCl}, 0.05 \mathrm{M}$ sodium acetate $(\mathrm{pH} 6.0)$ containing $0.5 \%(\mathrm{w} / \mathrm{v})$ Triton $\mathrm{X}-100$ as previously described. ${ }^{16}$ The fractions $(0.4 \mathrm{~mL}$ each $)$ were collected and counted.

\section{Enzymatic treatment of PGs}

$\left[{ }^{35} \mathrm{~S}\right]$-labeled macromolecules from the Sephadex G-50 columns were dialyzed against $0.1 \mathrm{M}$ Tris-acetate buffer $(\mathrm{pH} 7.3)$ and digested with chondroitinase ABC (Seikagaku, Tokyo, Japan) (10 $\mathrm{mU} / \mu \mathrm{L})$ with protease inhibitors $(10 \mathrm{mM}$ EDTA, $10 \mathrm{mM} \mathrm{N}$ ethylmaleimide, $5 \mathrm{mM}$ phenylmethylsulphonyl fluoride, $0.36 \mathrm{mM}$ pepstatin A). One part of the chondroitinase ABC-digested samples was further digested with heparitinase (Seikagaku, Tokyo, Japan) $(10 \mathrm{mU} / \mu \mathrm{L})$ and/or keratanase (Seikagaku, Tokyo, Japan) (10 $\mathrm{mU} / \mu \mathrm{L})$ at $37^{\circ} \mathrm{C}$ for an additional $2 \mathrm{~h}$. Finally, the enzyme-treated samples were subjected to the Superose 6 column.

\section{Polyacrylamide gel electrophoresis (SDS-PAGE)}

Heparitinase-treated samples were applied to precast 5-20\% gradient gels (Atto, Tokyo, Japan) and run at a constant current of $30 \mathrm{~mA}$. Pre-stained molecular weight markers were used as standards (Life Technologies: Thermo Fisher Scientific). After electrophoresis, the gels were dried for $2 \mathrm{~h}$ at $60^{\circ} \mathrm{C}$, then placed on an imaging plate (Fuji IP IN cassette) and analyzed by FCR PRIMA T2 (Fujifilm Medical, Tokyo, Japan).

\section{Results}

\section{In situ hybridization in mouse molar tooth germ}

All terms related to tooth germ morphogenesis are according to Pieco and Avery. ${ }^{15}$ At E13.5, the lower first molar tooth germ consisting of an epithelial tooth bud and condensed mesenchyme (future dental papilla) was at the bud stage, and mandibular bone started to surround it (Figure 1 a,f) Decorin, biglycan, and fibromodulin mRNAs were expressed in various tissues in the mandible (Figure $1 \mathrm{~b}-\mathrm{d}$ ). Focusing on tooth germ, decorin mRNA was expressed in the surrounding mesenchyme, but not within the tooth germ (Figure 1g), Biglycan mRNA was well expressed in the condensing mesenchyme of the tooth germ, but was not expressed within the epithelial tooth bud (Figure 1h). Fibromodulin mRNA did not show significant expression within the tooth germ (Figure 1i). Lumican mRNA did not show significant expression in any regions at this stage (Figure 1e). This was similar for lumican mRNA at all stages examined in the present study (data not shown). Since each mRNA showed similar expression patterns at E15.0 and E16.0, we describe results at E16.0 as representative. At E16.0, the masseter muscle was attached to the developing mandibular bone, which surrounded the tooth germ in the late cap stage (Figure 2 a,e). Decorin mRNA was expressed in the mesenchyme around the tooth germ, although not within it (Figure 2 b,f). Biglycan mRNA showed expression patterns similar to those of decorin; however, it was additionally expressed in the dental papillae (Figure $2 \mathrm{c}, \mathrm{g}$ ). Fibromodulin mRNA did not show significant expression within the tooth germ (Figure $2 \mathrm{~h}$ ). Note that each mRNA was expressed in the epimysium of the masseter muscle (Figure $2 \mathrm{~b}$-d). At E18.5, the tooth germ was in the apposition stage (late bell stage), and predentin formation with differentiating odontoblasts was evident at the cusp tip (Figure 3a). Decorin mRNA was well expressed in 
differentiating odontoblasts, as well as in the dental papilla beneath the odontoblastic layer at the cusp region (Figure 3b). However, biglycan mRNA was expressed at a lesser intensity than decorin and was only localized to odontoblasts at the cusp tips (Figure 3c). Fibromodulin mRNA was expressed in the epimysium of the masseter muscle, although not within the tooth germ (Figure 3d). Note that the epimysium also showed decorin and biglycan mRNA (Figure 3 b,c). At P1.0, dentin formation was clearly evident (Figure
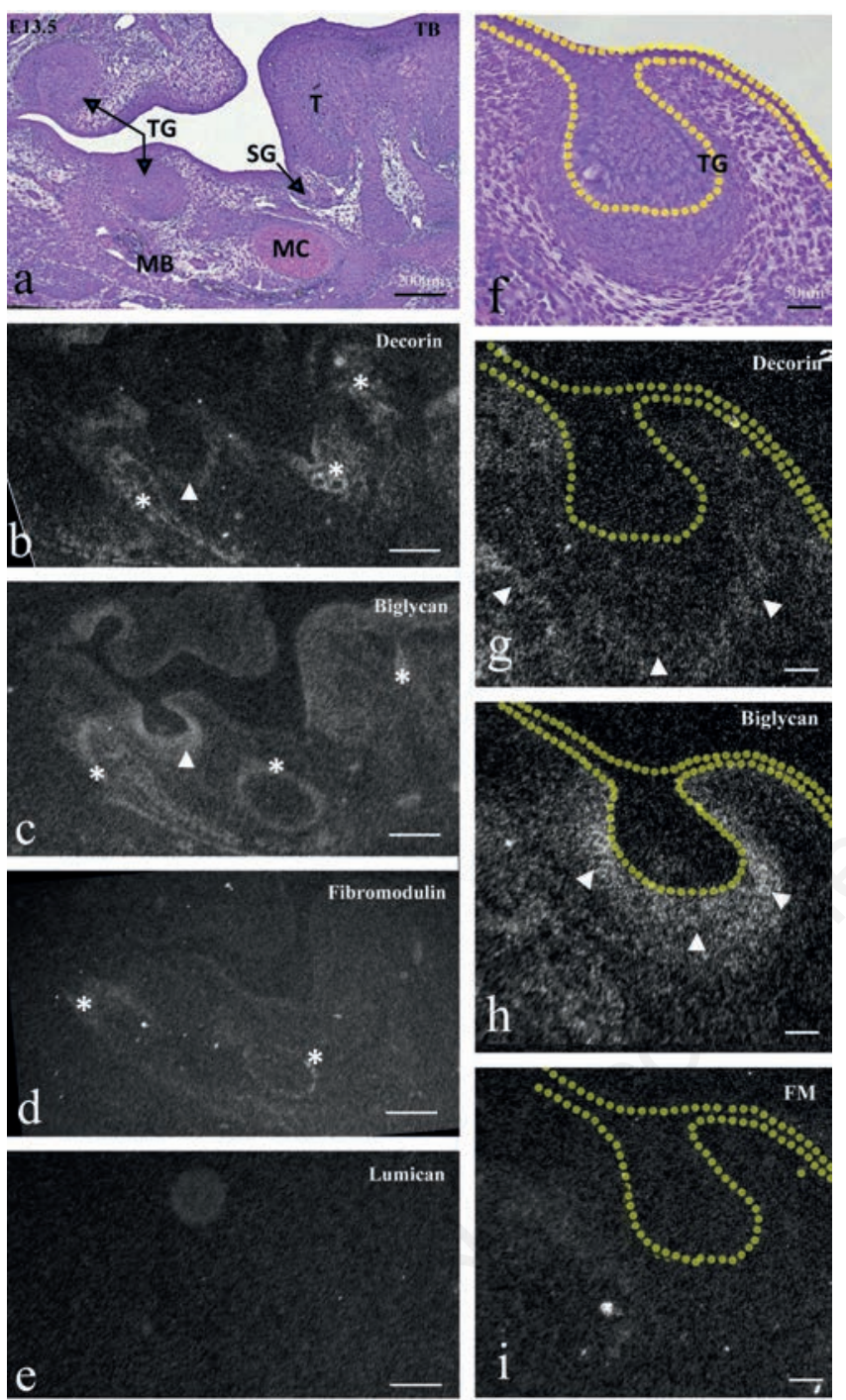

Figure 1. Frontally cut mouse head (a-e) and enlargement of lower molar tooth germ (TG) (f-i) at E13.5. TB staining $(a, f)$ and in situ hybridization for decorin mRNA (b,g), biglycan mRNA (c,h), fibromodulin mRNA (d,i), and lumican mRNA (e), a,f) Tooth germ at the bud stage, developing tongue muscle (T), and mandibular bone (MB) with Meckel's cartilage (MC) were seen. b,g) Decorin mRNA was expressed in tongue muscles, surrounding mesenchyme of the submandibular gland, developing mandibular bone (asterisks), and mesenchyme around tooth germ (arrowheads). c,h) Biglycan mRNAs was expressed in the lingual septum, perichondrium of Meckel's cartilage, developing mandibular bone (asterisks), and condensing mesenchyme of the tooth germ (arrowheads). d,i) Fibromodulin mRNA was weakly expressed in the perichondrium of Meckel's cartilage and the mandibular bone (asterisks), but not in the tooth germ. e) Lumican mRNA did not show significant expression. Scale bars: a-e) $200 \mu \mathrm{m}$; f-i) $80 \mu \mathrm{m}$. 3e). Decorin mRNA expression was reduced in mature odontoblasts facing dentin; however, it remained well expressed in the newly differentiating odontoblasts towards the cervical part of the tooth germ (Figure 3f). In contrast, biglycan expression was enhanced in the mature odontoblasts, but remained weakly expressed in the newly differentiating odontoblasts (Figure 3g). Decorin and biglycan mRNA were also detected in the dental papillae beneath the odontoblastic layers; however, the expression of the former was slightly stronger than the latter (Figure $3 \mathrm{f}, \mathrm{g}$ ). The epimysium was found to still express every mRNA examined at this stage (Figure 3 f-h). At P3.0, dentin, as well as enamel formation, were evident (Figure 4a). Strong decorin mRNA expression was localized in the newly differentiating odontoblasts at the cervical region (Figure $4 \mathrm{~b}$ ). Meanwhile, biglycan mRNA was expressed strongly throughout the odontoblastic layer (Figure 4c). The dental papillae showed similar expression patterns for decorin and biglycan to those at P1.0 (Figure 4 b,c). Fibromodulin mRNA was expressed in the epimysium, but it was not expressed within the tooth germ (Figure 4d). Notably, not every mRNA was expressed at all stages in the ameloblasts (Figure 4 b-d).

At P7.0, crown formation was found to have advanced, with Hertwig's epithelial root sheath having started to form (Figure 4e). Decorin mRNA expression was completely reduced, although it remained at the cervical tip, that is, where the new odontoblasts were being differentiated (Figure 4f). Biglycan mRNA expression was also reduced, although it remained weakly expressed throughout the odontoblastic layer (Figure 4g). The dental papilla at the coronal region weakly expressed decorin and biglycan mRNAs (Figure $4 \mathrm{f}, \mathrm{g}$ ).

\section{In situ hybridization in mouse incisor tooth germ and} in lower limb tendons and epimysium

The incisor tooth germ at P7.0 cut at the sagittal plane showed every stage of differentiating odontoblast (Figure 5a). Decorin
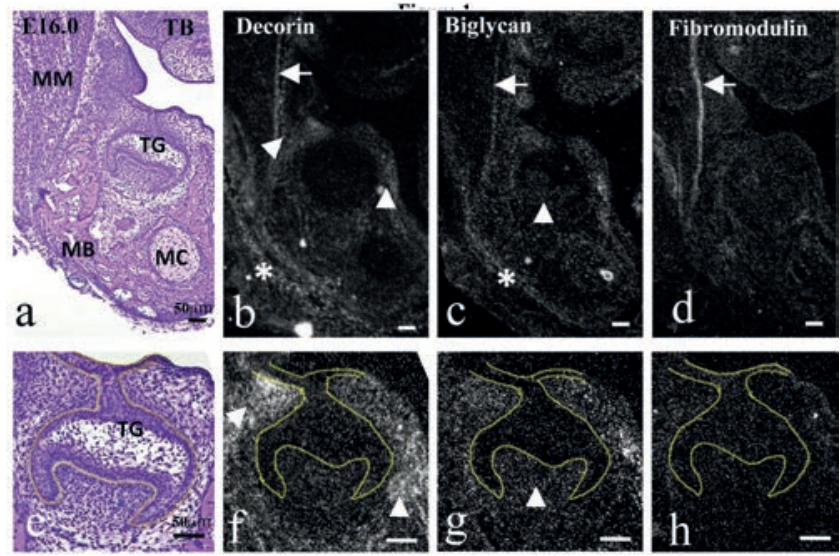

Figure 2. Frontally cut mouse head (a-d) and magnification of lower molar tooth germ (TG) (e-h) at E16.0. TB staining (a,e) and in situ hybridization for decorin (b,f), biglycan $(\mathrm{c}, \mathrm{g})$, and fibromodulin mRNA (d,h). a,e) Masseter muscle (MM) was attached to developing mandibular bone (MB); developing tooth germ was in the late cap stage. a-h) Decorin mRNA was expressed in the periosteum of the mandibular bone (asterisk in b), and the mesenchyme around the tooth germ (arrowheads in b and f). Biglycan mRNA was expressed in the periosteum of the mandibular bone (asterisk in c), and additionally in dental papillae (arrowheads in $\mathrm{c}$ and g). Fibromodulin mRNA was not expressed in tooth germ. Note that three mRNAs were expressed in the epimysium of the masseter muscle (arrows in b-d). Scale bars: $50 \mu \mathrm{m}$. 
mRNA expression was detected in newly differentiating odontoblasts, although it was gradually reduced towards the coronal region (Figure 5b). Biglycan mRNA expression started to be detected in odontoblasts at a similar position to that showing decorin
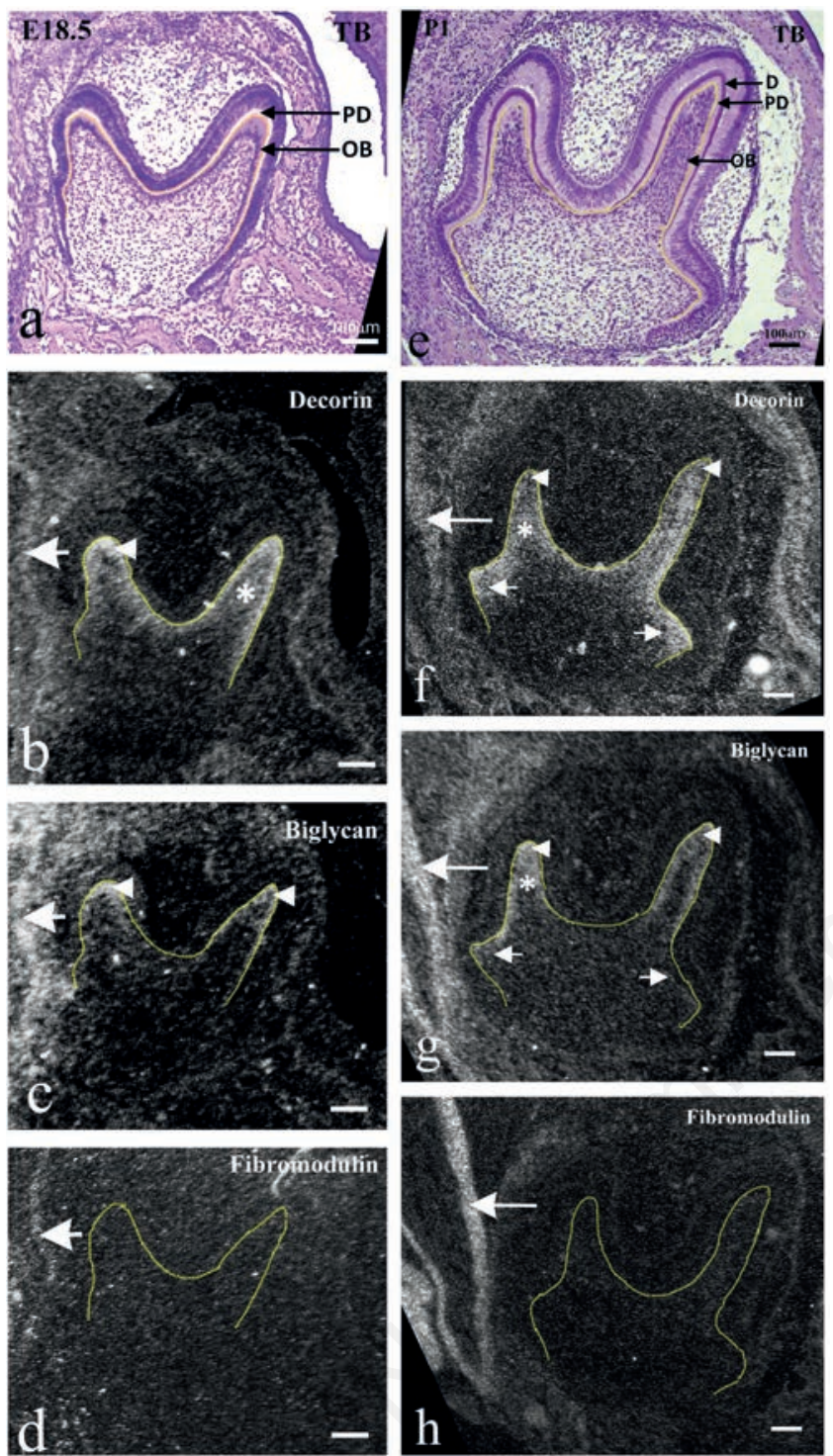

Figure 3. Frontally cut mouse lower molar tooth germs at E18.5 (ad) and at P1.0 (e-h). TB staining (a,e) and in situ hybridization for decorin (b,f), biglycan (c,g) and fibromodulin mRNA (d, h). a e) Odontoblasts (OB) with formation of predentin (PD) and/or dentin (D) were evident at cusp tips. b-d) Decorin mRNA was well expressed in differentiating odontoblasts at cup tips (arrowhead in b) and dental papillae beneath them (asterisks in b); biglycan mRNA was expressed at low intensity in differentiating odontoblasts (arrowheads in c); fibromodulin mRNA was not expressed within the tooth germ. $\mathrm{f}-\mathrm{h}$ ) Decorin $\mathrm{mRNA}$ expression was reduced in mature odontoblasts (arrowheads in f), but extended to newly differentiating odontoblasts in the cervical region (arrows in $\mathrm{f}$ ) and also in the dental pulp beneath odontoblasts (asterisks in f); biglycan mRNA expression was enhanced in mature odontoblasts (arrowheads in g) and underlying dental pulp (asterisks in g), but still weak in newly differentiating odontoblasts (arrows in $\mathrm{g}$ ); fibromodulin mRNA was not expressed within the tooth germ. All mRNAs were expressed in the epimysium of masseter muscles (large arrows in b-d, f-h). Scale bars: $100 \mu \mathrm{m}$.
mRNA expression; however, the odontoblasts maintained biglycan mRNA expression more towards the tip region compared to decorin (Figure $5 \mathrm{c}$ ). The tendon of the quadriceps femoris muscle was continuous to the epimysium of the tibialis anterior muscle at P1.0
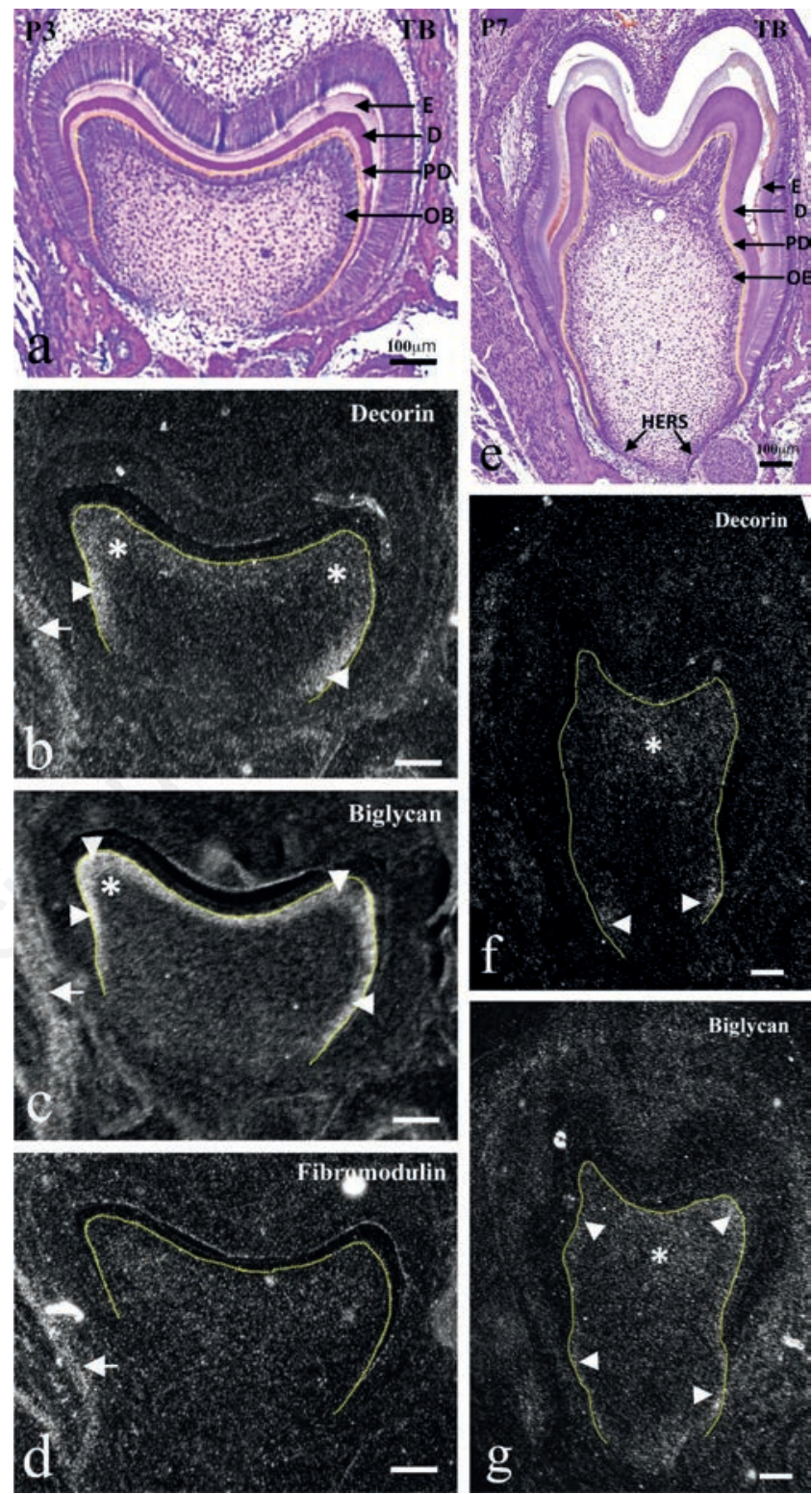

Figure 4. Frontally cut mouse lower molar tooth germs at P3.0 (ad) and P7.0 (e-g). TB staining (a,e) and in situ hybridization for decorin (b,f), biglycan (c,g), and fibromodulin mRNA (d). a,e) Dentin (D) and enamel (E) formation were evident, and Hertwig's epithelial root sheath (HERS) had started to form. bd) Decorin mRNA expression was localized in the newly differentiating odontoblasts at the cervical region (arrowheads in b) and underlying pulp (asterisks in b); biglycan mRNA was expressed strongly throughout the odontoblast layer (arrowheads in c) and underlying pulp (asterisks in c); fibromodulin mRNA was not expressed within the tooth germ $(\mathrm{d})$. f,g) Decorin mRNA expression only remained in odontoblasts at the cervical tip (arrowheads in $\mathrm{f}$ ) and weakly in the coronal pulp (asterisk in f); biglycan mRNA expression was also reduced, but remained weak throughout the odontoblast layer (arrowheads in $\mathrm{g}$ ) and in the coronal pulp (asterisk in g). Epimysium of masseter muscles expressed all three mRNAs (arrows in b-d). OB, odontoblasts; PD, predentin. Scale bars: $100 \mu \mathrm{m}$. 
(Figure 5d). The tendon, the epimysium, and the perimysium all expressed decorin, biglycan, and fibromodulin mRNA, although the expression of decorin mRNA was weak in the epimysium while strong in the perimysium (Figure $5 \mathrm{e}-\mathrm{g}$ ).

\section{Immunohistochemistry in mouse molar tooth germ}

At E16.0, although biglycan immunoreactivity was detected in the dental papilla, other immunoreactivities were not detected within the tooth germ (Figure 6 a-d). Despite this, decorin immunoreactivity was detected in the lamina propria of the oral mucosa around the tooth germ (Figure 6a). These findings correlated with mRNA expression patterns; however, in contrast to the mRNA findings, lumican immunoreactivity was detected in the osteoid of the mandibular bone (Figure 6d). At E18.5, immunoreactivity for four SLRPs was detected in the predentin and osteoid (Figure $6 \mathrm{e}-\mathrm{h}$ ). These results were in accordance with mRNA expression for decorin and biglycan in odontoblasts, indicating that these molecules were mainly synthesized by odontoblasts, but not in accordance with the mRNA expression for fibromodulin and lumican.

Biglycan immunoreactivity was also detected in the central region of the dental pulp; however, it was weakly expressed in the peripheral region beneath the odontoblastic layer where its mRNA expression was clearly detected (Figure 6f). From P1.0 (data not shown) to P3.0, immunoreactivities showed similar expression patterns to those at E18.5. Notably, immunoreactivity was detected neither in the dentin nor in the enamel (Figure 6 i-1).

\section{Analysis of SLRPs synthesized by tooth germ explants}

In the explant cultures, the amount of $\left[{ }^{35} \mathrm{~S}\right]$-labeled macromolecules released into the explants at E18.0 was significantly larger than that at E16.0, and that at P3.0 was further
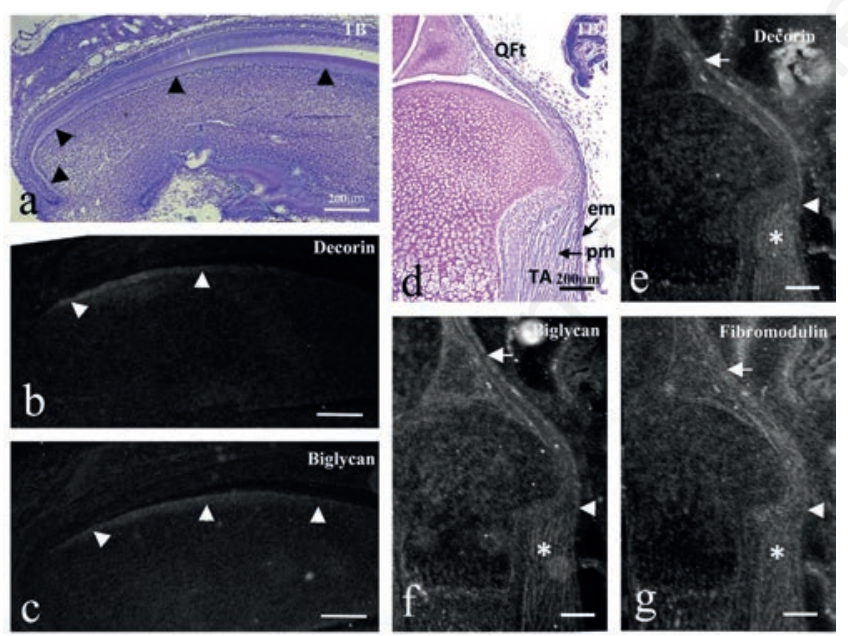

Figure 5. Sagittally cut mouse incisor tooth germ at P7.0 (a-c) and sagittally cut mouse lower limb at P1.0 (d-g). TB staining (a,d) and in situ hybridization for decorin $(\mathrm{b}, \mathrm{e})$, biglycan $(\mathrm{c}, \mathrm{f})$, and fibromodulin mRNA (g). a) All differential stages of odontoblasts can be identified (arrowheads in a). b, c) Decorin mRNA was expressed in newly differentiating odontoblasts and reduced towards the coronal region (arrowheads in c); biglycan mRNA was also expressed in odontoblasts and maintained its reactivity more towards the tip region (arrowheads in c). d) Tendons of the quadriceps femoris muscle $(\mathrm{QFt})$ were continuous to the epimysium (em) of the tibialis anterior muscle (TA). e-g) Three mRNAs were expressed in the tendons (arrows), the continuous epimysium (arrowheads), and in the perimysium (asterisks), although decorin was weakly expressed in the epimysium (arrowhead in e). Scale bars: $200 \mu \mathrm{m}$. significantly larger than that at E18.0, indicating that the amount of synthesized macromolecules increased in association with tooth germ growth (Figure 7a). A $\left[{ }^{35} \mathrm{~S}\right]$-labeled tissue sample from each day was analyzed by Superose 6 gel chromatography (Figure 7b). Intact samples from E16.0 and E18.0 showed similar elusion profiles. In both samples, a major peak eluted at V0 (peak 1) and a broad peak eluted at $K_{d}=0.23$ (peak 2) were observed. The ratios of $\left[{ }^{35} \mathrm{~S}\right]$ radioactivity in peaks 1 and 2 to total radioactivity were $\sim 69 \%$ and $\sim 29 \%$ at E16.0 and $\sim 51 \%$ and $\sim 39 \%$ at E18.0, respectively. Peaks 1 and 2 at E16.0 were somewhat susceptible to chondroitinase $\mathrm{ABC}$, while only $\sim 5 \%$ of $\left[{ }^{35} \mathrm{~S}\right]$ radioactivity remained in the regions of peaks 1 and 2 and was not susceptible to digestion by heparitinase or keratanase, indicating small amounts of synthesized HS-PGs and KS-PGs. At E18.0, $\sim 27 \%$ of $\left[{ }^{35} \mathrm{~S}\right]$ radioactivity remained in peak 1 and 2 regions after chondroitinase $\mathrm{ABC}$ digestion. About $10 \%$ of $\left[{ }^{35} \mathrm{~S}\right]$ radioactivity in the remaining peaks was susceptible to heparitinase; however, it was not

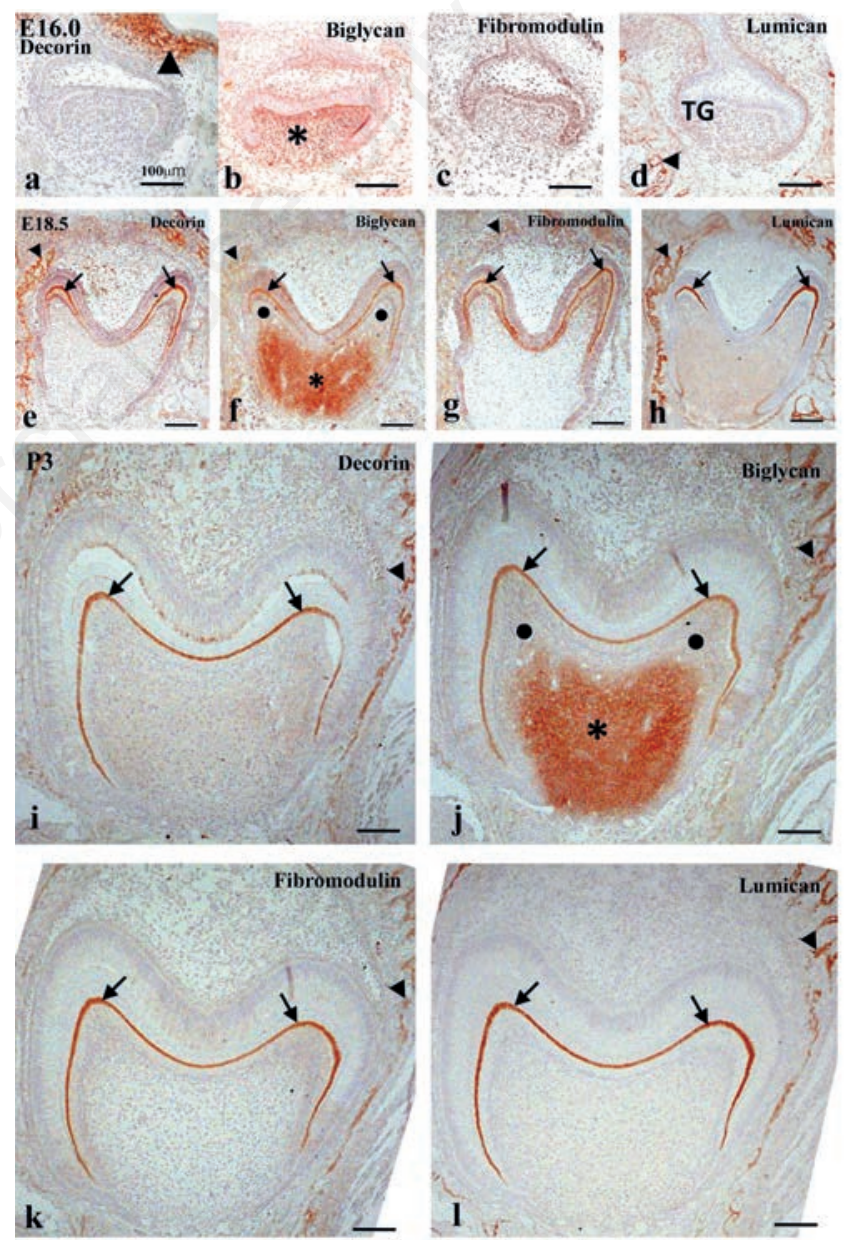

Figure 6. Immunohistochemistry in frontally cut mouse molar tooth germs at E16.0 (a-d), E18.5 (e-h), and P3.0 (i-1) for decorin $(a, e, i)$, biglycan $(b, f, j)$, fibromodulin $(c, g, k)$, and lumican $(d, h, l)$ proteins. a-d) Decorin immunoreactivity was detected in the lamina propria of oral epithelium (arrowhead in a); biglycan immunoreactivity was detected in the dental papillae (asterisk in b). Lumican immunoreactivity was detected in the osteoid (arrowhead in d). e-1) Immunoreactivity for all SLRPs was detected in the predentin (arrows) and osteoid (arrowheads); biglycan immunoreactivity was additionally detected in the central region of the dental pulp (asterisks in $f$ and $j$ ), but not in the peripheral region (black circles in $f$ and $j$ ). Scale bars: $100 \mu \mathrm{m}$. 
susceptible to subsequent digestion by keratanase, indicating that a significant amount of HS-PGs was synthesized, while KS-PGs was synthesized at low levels. In addition, a third peak was disclosed at $\mathrm{K}_{\mathrm{d}}=0.68$ after chondroitinase $\mathrm{ABC}$ digestion and was not susceptible to either heparitinase or keratanase. The remaining peaks at the 1 and 2 regions and peak 3 may represent sulfated proteins or sulfated glycoproteins. However, the necessary analyses for their elucidation did not fall within the scope of this study. At P3.0, peak 1 became small, while other peaks were recognized at $\mathrm{K}_{\mathrm{d}}=0.48$ (peak 4) and $K_{d}=0.70$ (peak 5). Since these peaks were not susceptible to enzymatic treatments, they may represent sulfated proteins or glycoproteins. Peaks 1 and 2 were susceptible to chondroitinase $\mathrm{ABC}$. The remaining peak $(\sim 11 \%)$ was further susceptible to heparitinase, but was not susceptible to keratanase, indicating that significant amounts of HS-PGs were also synthesized, while KS-PGs were synthesized at low levels

\section{SDS-PAGE analyses}

Since the specimens investigated above were found to potentially contain significant amounts of HS-PGs, they were subjected to SDS-PAGE after heparitinase digestion. One band outside the gel (band 1) and two broad bands [ 250 kDa (band 2) and $\sim 100 \mathrm{kDa}$ (band 3)] were observed in all three stages (Figure 7c). Compared to E16.0 and E18.0, band 2 of P3.0 was significantly thicker than band 3. According to previous studies ${ }^{36,37}$ bands 1,2 , and 3 correspond to versican-type large PG, biglycan-type small $\mathrm{PG}$, and decorin-type small PG, respectively. Hence, the tooth germ at P3.0 synthesized higher amounts of biglycan-type PG than decorin-type PG.

\section{Discussion}

\section{Expression of decorin and biglycan mRNAs in} odontoblasts with the formation of predentin/dentin

In the present study, decorin and biglycan mRNAs were more highly expressed than fibromodulin and lumican mRNAs in developing mouse molar tooth germ. In addition, the explant cultures indicated that KS-PGs were synthesized at low levels by tooth germs from E16.0 to P3.0, suggesting that the involvement of KS-PGs (e.g. fibromodulin and lumican) in tooth formation was less than that of CS-PGs (e.g. versican, decorin, and biglycan). Although a previous study reported that fibromodulin mRNA is expressed in the outer enamel epithelium and lumican mRNA in the dental papillae of E14.5 mice incisors, ${ }^{28}$ our results suggest that tooth germs express fibromodulin and lumican mRNAs in small amounts, a

$\left.{ }^{35} \mathrm{~S}\right]$ incorporation into macromolecules

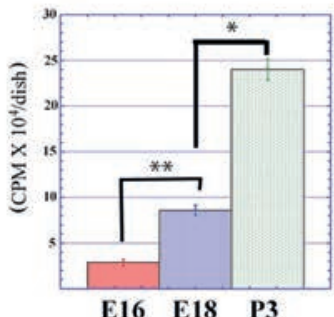

c

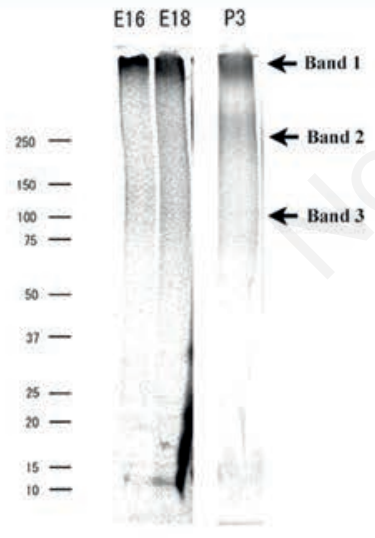

b

E16
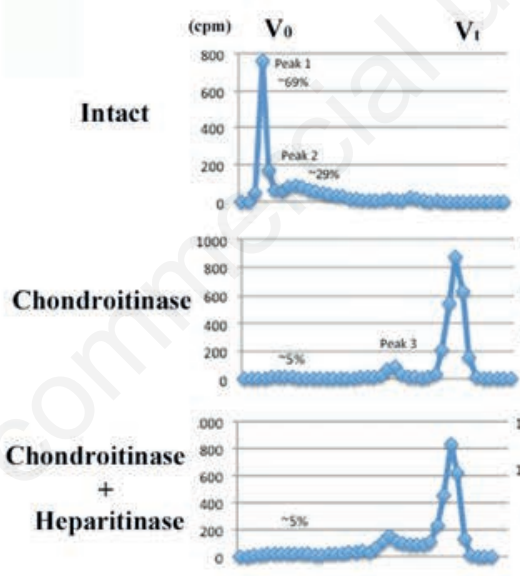

Chondroitinase
+
Heparitinase

$+$

Keratanase

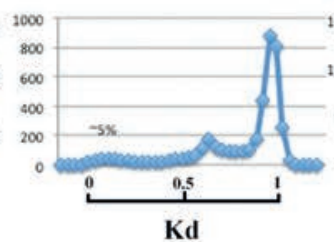

E18
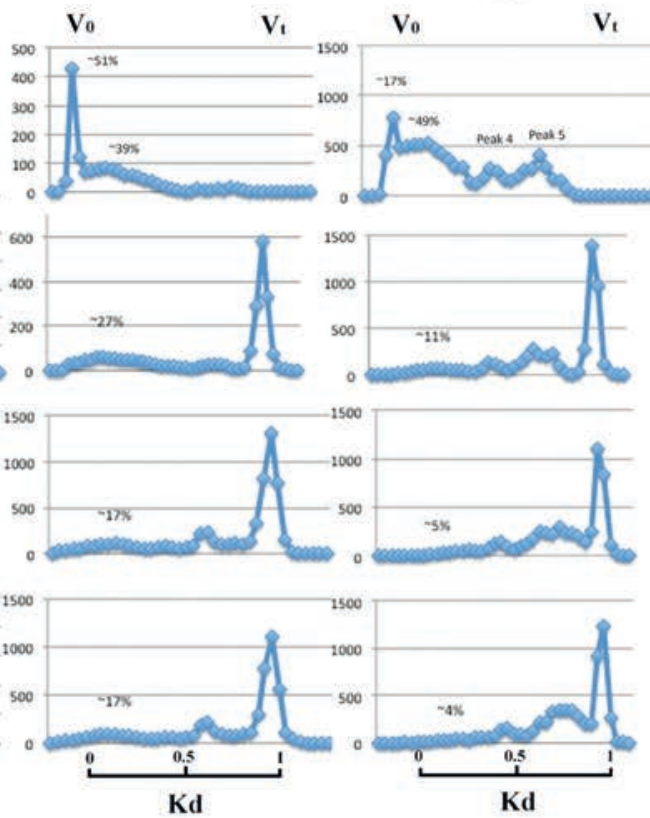

P3
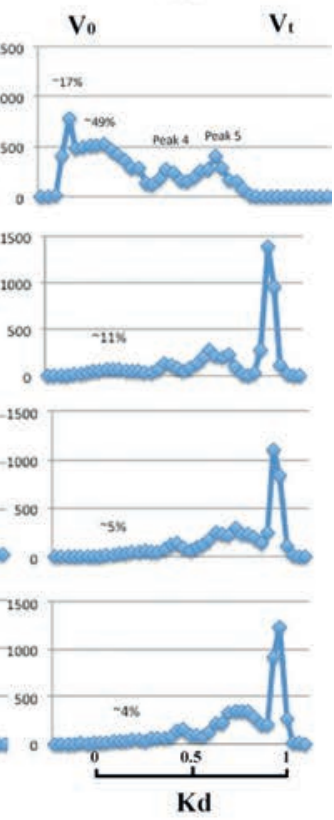

Figure 7. a) $\left.{ }^{35} \mathrm{~S}\right]$-labeled macromolecules released into explants at E16.0, 18.0, and P3.0. From E16.0 to E18.0, the amount of macromolecules was significantly increased, and was further increased at P3.0 compared with E18.0; data are presented as means \pm SD ( $\mathrm{n}=$ 4); ${ }^{*} \mathbf{P}<\mathbf{0 . 0 1}$, significantly different between indicated groups; ${ }^{* *} \mathbf{P}<\mathbf{0 . 0 5}$, significantly different between indicated groups. $\left.\mathbf{b}\right)$ Superose 6 elution profiles of explants from E16.0, 18.0, and P3.0 with or without enzymatic treatments; peaks 1 and 2 in E16.0 samples were slightly susceptible to chondroitinase $\mathrm{ABC}$, and remaining peaks at 1 and 2 regions were not susceptible to digestion of heparitinase and keratanase. In E18.0 samples, remaining peaks at 1 and 2 regions after chondroitinase ABC digestion, were susceptible to heparitinase $(-10 \%)$, but were not susceptible to subsequent digestion by keratanase. Peak 3 was not susceptible to either heparitinase or keratanase; in the P3.0 sample, peak 1 became small and peaks 1 and 2 were largely susceptible to chondroitinase ABC, and remaining peaks were further susceptible to heparitinase, but not susceptible to keratanase; peak 4 and 5 were also recognized, but were not susceptible to any enzymatic treatment. c) SDS-PAGE analysis; a band at the top of the gel (band 1), and two broad bands of $\sim 250 \mathrm{kDa}$ (band 2) and $\sim 100 \mathrm{kDa}$ (band 3), were recognized for all three ages. Compared to E16.0 and E18.0, band 2 of P3.0 was significantly thicker than band 3. 
as they were observed at a low intensity during our procedure. Thus, the relationship of decorin and biglycan to tooth formation was the main focus of the present study.

As biglycan mRNA was expressed at every developmental stage of the mouse molar tooth germ, we considered it to be the most abundant molecule among the four SLRPs examined. Notably, decorin and biglycan mRNAs were found to be differentially expressed in odontoblasts. At the predentin formation stage (E18.5), decorin mRNA was well expressed in the differentiating odontoblasts at the cusp tip, while the expression of biglycan mRNA was low. With the formation of dentin (P1.0 to 3.0), decorin mRNA expression was decreased in that area, being more localized to the newly differentiating odontoblasts towards the cervical part of the tooth germ. Simultaneously, biglycan mRNA expression became more intense, being expressed throughout the new and mature odontoblasts. This change in the pattern of expression strongly supports the idea that they play different roles in tooth formation by regulating odontoblast differentiation, as we hypothesized.

The expression of decorin and biglycan mRNAs in odontoblasts has been previously reported. ${ }^{29,30}$ Hikake et al. ${ }^{30}$ reported changes in the expression of decorin and biglycan mRNAs in the odontoblasts of mouse molar tooth germs from E18.5 to P4.5. Although their findings partially correlate with the results presented here, they mainly focused on the co-expression of decorin/biglycan mRNA with OASIS mRNAs, without referring to the distinct expression patterns between decorin and biglycan. Matsuura et al. ${ }^{29}$ found that decorin and biglycan show distinct expression patterns, proposing that these molecules have different roles in odontoblast differentiation. Although we agree with their hypothesis, the expression patterns described in their study were slightly different from our own findings. Matsuura et al. ${ }^{29}$ demonstrated that biglycan mRNA is expressed in presecretory odontoblasts and is weak in secretory odontoblasts, whereas decorin mRNA is highly expressed in secretory odontoblasts. They used an upper first molar at E19.0 (newborn) as the dentin-secretory stage, with their results being mostly consistent with ours at E18.5. Furthermore, they used a lower incisor at E19.0 as the later stage (dentin/enamel secretory stage), obtaining the above results. We investigated changes in the temporal expression patterns in identical tooth germs (lower first molars), resulting in the expression patterns described above. The incisor results correlated with the fact that biglycan mRNA is expressed in mature odontoblasts at later stages.

The differentiation of dental papillae cells at the interface with the enamel organs results in the appearance of odontoblasts, which subsequently secrete predentin matrix. ${ }^{15}$ To assess the function of decorin and biglycan in tooth formation, Goldberg et al. ${ }^{25}$ analyzed both decorin-deficient and biglycan-deficient mice. They performed immunohistochemistry for decorin and biglycan in molar tooth germs of wild-type mice at P1.0; they described strong immunoreactivities for both molecules in predentin and weak biglycan immunoreactivity in odontoblasts and enamel organs including ameloblasts, stratum intermedium, and stellate reticulum. Except for biglycan immunoreactivity in dental papillae (discussed later), our results did not show immunoreactivity in tissues other than predentin. This slight discrepancy may be due to the different antibodies used or our pre-treatment of sections with hyaluronidase. In any case, our immunohistochemistry results from E18.5 to P3.0 agreed with those of Goldberg et al. ${ }^{25}$ in that predentin showed strong immunoreactivity for both molecules, and our in situ hybridization results confirmed that they are mainly secreted by odontoblasts.

Based on analyses of gene-knockout mice, Goldberg et al. ${ }^{25}$ suggested the involvement of decorin and biglycan in enamel formation; the former accelerates it, but the latter inhibits it. Our results indicate that the abnormality of enamel formation in their gene-knockout mice seems to have been due to an impairment of dentin/predentin formation, since we recognized no significant mRNA expression for either molecule in ameloblasts. In contrast to our results, Matsuura et al. ${ }^{29}$ reported biglycan mRNA expression in ameloblasts. While Matsuura et al. ${ }^{29}$ used digoxigenin-labeled probes for cryo-sections, we used RI-labeled probes for paraffin sections. As such, this discrepancy may be the result of the use of different probes and/or labeling methods. Since significant immunoreactivity was not detected in the enamel matrix or ameloblasts, we believe that ameloblasts synthesize and secrete only small amounts of SLRPs, including biglycan.

Goldberg et al. ${ }^{25}$ also demonstrated that biglycan, but not decorin, controls collagen fibrogenesis in predentin, and that decorin, and to a lesser extent biglycan, promote dentin mineralization. The functions of decorin and biglycan in these phenomena are somewhat controversial according to previous studies. Some studies suggest that decorin regulates collagen fibrillogenesis by binding to many types of collagen, including types I, II, and III. ${ }^{38}$ In the absence of decorin, irregular collagen contours and diameters arise in various types of tissues, including the skin and tendons, as well as in the periodontal ligaments. ${ }^{9,26}$ An in vivo study indicated that decorin is a negative regulator of mineralization, ${ }^{39}$ but an in vitro study indicated that decorin had no effect on mineral accumulation. ${ }^{40}$ Decorin-deficient mice do not show osteoporosis-like phenotypes. ${ }^{25}$ Biglycan however has been suggested to be an accelerator of matrix mineralization, ${ }^{40}$ and biglycan-deficient mice show osteoporosis-like phenotype ${ }^{10}$ and also have hypomineralized dentin..$^{25,41}$

Immunohistochemistry analysis showed both decorin and biglycan immunoreactivity in the predentin, although not in mineralized dentin. Similar results have been reported by previous studies in mouse molars, ${ }^{25,42}$ mouse incisors, ${ }^{23}$ and rat molars. ${ }^{21}$ These results also support the hypothesis that both molecules are involved in dentin formation in terms of predentin formation and/or its mineralization.

These complicated results may indicate discrepancies between in vitro and in vivo experiments or between dentin and bone. In any case, our histological study cannot confirm whether the proposed hypotheses are correct or not, but at least it indicates that predentin/dentin formation may progress via two steps: a decorinprevailing initial step and a biglycan-prevailing subsequent step. It is well known that the two mechanisms achieve mineralization; the first involves matrix vesicles, and the second involves heterogenous nucleation along with collagen fibrils, and this is used in dentin mineralization. ${ }^{43}$ The present results can classify the second step into further two steps. Further studies, however, are required to clarify this hypothesis while taking the relationship between decorin/biglycan and small integrin-binding ligand N-linked glycoproteins (SIBLINGs) into consideration, since SIBLINGs are known to be involved in dentin mineralization. ${ }^{25,41}$

Furthermore, Goldberg et al. ${ }^{25}$ found that dentin hypomineralization observed in newborn mice with decorin and biglycan gene-knockout had undergone self-repair in adult mice, suggesting that decorin and biglycan may be involved in the initial process of mineralization, but that it is subsequently taken over by other molecules. In the present study, mRNA expression for both molecules was reduced at P7.0 despite dentin formation being a continuous process, which further supports this hypothesis.

\section{Expression of decorin and biglycan mRNA/proteins in dental papillae/dental pulp}

The present study showed that both decorin and biglycan mRNA were expressed in the dental papillae beneath the odontoblastic layers at the cusp regions, in line with their strong expression in odontoblasts. However, immunohistochemistry analyses indicated that only biglycan immunoreactivity was 
consistently present in the dental papillae/pulp. Goldberg et al. ${ }^{25} \mathrm{did}$ not report biglycan immunoreactivity in the dental papillae of wildtype mice at P1.0. This may be due to pretreatment of sections with hyaluronidase in the present study, since GAG chains of proteoglycans often block immunoreactivity of core proteins. ${ }^{44}$ At E18.5, biglycan was strongly expressed in the central region, but was weak in the peripheral region beneath the odontoblastic layer, indicating that the dental pulp cells beneath the odontoblastic layer may secrete biglycan protein into the central region.

The distribution patterns of biglycan immunoreactivity in the dental pulp were similar to those of versican ${ }^{16}$ or perlecan. ${ }^{17}$ Filling spaces for the development of organs appears to be an important function of large PGs, such as versican. ${ }^{45}$ Thus, biglycan may be related to the development of dental papillae/pulp together with other PGs. The region immediately below the odontoblast layer is known as the cell-rich zone. ${ }^{15}$ Cells in this zone are capable of differentiating into odontoblasts when the initial cells are damaged, and may be involved in the transport and reabsorption of fluid and ions from the pulp to odontoblastic layer. ${ }^{46,47}$ Thus, decorin and/or biglycan may also exert such functions. Future experimental studies that induce damage to the dental pulp and accelerate tissue repair may clarify this hypothesis.

\section{Protein synthesis analyzed by organ culture with meta- bolic labeling of $\left[{ }^{35} \mathrm{~S}\right]$}

In the present study, compared to CS-PGs, KS-PGs were found to be synthesized at low levels by tooth germs from E16.0 to P3.0. These results support the in situ hybridization results, wherein the expression of fibromodulin and lumican mRNA were not detected at any stage of the tooth germs examined. Significant amounts of HS-PGs, however, were synthesized by tooth germs at E18.0 and P3.0. Ida-Yonemochi et al. ${ }^{17}$ investigated the expression and synthesis of perlecan, a representative large HS-PG, and demonstrated its involvement in tooth formation. Furthermore, the expression of the syndecan family, which are principal cell-surface HS-PGs, has also been reported in the developing tooth germ, ${ }^{48,18}$ indicating that the HS-PGs synthesized in the present study may correspond to these types of PGs. In addition, sulfated proteins were synthesized by the tooth germ at P3.0. Previous studies have suggested that bone/tooth-related proteins, such as bone sialoprotein (BSP), often undergo sulfation. ${ }^{49}$ Thus, the sulfated proteins in the present study may correspond to these proteins. Further structural analyses will be required to confirm the characteristics of these HSPGs or sulfated proteins. With regard to CS-PGs, we confirmed versican-type large PGs and biglycan- and decorin-type small PGs by SDS-PAGE. Among the two molecules, the biglycan-type PG was primarily synthesized by the tooth germ at P3.0, supporting our in situ hybridization and immunohistochemistry results at P3.0 showing that biglycan was predominant.

The incorporation of decorin/biglycan with growth factors has been previously reported in various cell types. ${ }^{2,50}$ In particular, decorin has been found to inhibit cell proliferation by activating EGF receptors ${ }^{51,52}$ such that the initial expression of decorin mRNA may play a role in maintaining the non-proliferative single layer of odontoblast cells. Further studies investigating the expression of growth factors will be required to test this hypothesis.

\section{Expression of fibromodulin and lumican}

Although fibromodulin and lumican mRNA were not detected, and the synthesis of KS-PGs was detected at low levels in the tooth germs of mice at P3.0, immunoreactivity to both molecules was observed in the predentin. This may be the result of a small amount of proteins being synthesized by the odontoblasts and accumulated in the predentin.

Previous immunohistochemical studies have demonstrated the presence of fibromodulin ${ }^{23,53}$ and lumican ${ }^{13}$ in the predentin.
Goldberg et al. ${ }^{53}$ demonstrated altered dentin mineralization in fibromodulin-deficient mice at P1.0, and hence insisted that fibromodulin regulates dentin mineralization and the early stages of enamel formation. In the present study, although the immunoreactivity of these two molecules was also detected in the osteoid of the mandibular bone, it was not detected in mineralized dentin or bone. This indicates that these molecules may be related to mineralization together with decorin/biglycan, supporting the theory presented by Goldberg et al. ${ }^{53}$

Although the expression of fibromodulin mRNA was not detected in the tooth germ, it was highly expressed in the epimysium of the masseter muscle at all stages examined and was co-expressed with decorin and biglycan mRNA. Similar expression patterns were also observed in the tendons of the quadriceps femoris muscle and in the epimysium of the tibialis anterior muscle, although the expression intensity varied between the different molecules. These results correlated with those reported by previous studies in which decorin, biglycan, and fibromodulin expression have been reported in muscles and tendons. ${ }^{54,55}$ The absence of their expression has been associated with altered collagen diameters and irregular collagen fibril outlines. ${ }^{56,57}$ Biglycan and fibromodulin double-knockout mice show an impaired gait, ectopic tendon ossification, and osteoarthritis phenotypes. ${ }^{58}$ These findings suggest that the co-expression of these three mRNAs seems to be a general structural feature in tendons and/or the epimysium, and they are involved in regulating fibrillogenesis and the inhibition of excessive mineralization. In this study, decorin, biglycan, and fibromodulin were not highly expressed in other epimysia of muscles in the craniofacial region (data not shown), indicating that the expression of these three SLRPs has muscle-specific variations.

To conclude, the present study suggests that SLRPs show different expression patterns in each stage of tooth development, suggesting that SLRPs may have their own tissue-specific roles. In particular, biglycan was found to be the most abundant molecule among the four SLRPs examined.

\section{Acknowledgements}

This work was supported by a Grant-in-Aid for Scientific Research (No. 18K06820) from the Ministry of Education, Culture, Sports, Science, and Technology of Japan.

\section{References}

1. McEwan P, Scott P, Bishop P, Bella J. Structural correlations in the family of small leucine-rich repeat proteins and proteoglycans. J Struct Biol 2006;155:294-305.

2. Schaefer L, Iozzo R. Biological functions of the small leucinerich proteoglycans: from genetics to signal transduction. J Biol Chem 2008;283:21305-9.

3. Nikitovic D, Aggelidakis J, Young M, Iozzo R, Karamanos N, Tzanakakis G. The biology of small leucine-rich proteoglycans in bone pathophysiology. J Biol Chem 2012;287:33926-33.

4. Chen S, Birk D. The regulatory roles of small leucine-rich proteoglycans in extracellular matrix assembly. FEBS J 2013; 280:2120-37.

5. Orsini G, Ruggeri A, Mazzoni A, Nato F, Manzoli L, Putignano, A et al. A review of the nature, role, and function of dentin non-collagenous proteins. Part 1: proteoglycans and glycoproteins. Endodontic Topics 2012;21:1-18.

6. Neame PJ, Kay CJ. Small leicine-rich proteoglycans. In: Iozzo RV, editor. Proteoglycans: Structure, biology, and molecular interactions. New York: Marcel Dekker, Inc.; 2000; p. 201-36. 
7. Mochida Y, Parisuthiman D, Pornprasertsuk-Damrongsri S, Atsawasuwan P, Sricholpech M, Boskey A, et al. Decorin modulates collagen matrix assembly and mineralization. Matrix Biol 2009;28:44-52.

8. Parisuthiman D, Mochida Y, Duarte W, Yamauchi M. Biglycan modulates osteoblast differentiation and matrix mineralization. J Bone Miner Res 2005;20:1878-86.

9. Danielson K, Baribault H, Holmes D, Graham H, Kadler K, Iozzo R. Targeted disruption of decorin leads to abnormal collagen fibril morphology and skin fragility. J Cell Biol 1997; 136:729-43.

10. Xu T, Bianco P, Fisher L, Longenecker G, Smith E, Goldstein $\mathrm{S}$, et al. Targeted disruption of the biglycan gene leads to an osteoporosis-like phenotype in mice. Nat Genet 1998;20:7882.

11. Goldberg M, Ono M, Septier D, Bonnefoix M, Kilts T, Bi Y, et al. Fibromodulin-deficient mice reveal dual functions for fibromodulin in regulating dental tissue and alveolar bone formation. Cells Tissues Organs 2009;189:198-202.

12. Goldberg M, Marchadier A, Vidal C, Harichane Y, KamounGoldrat A, Kellermann O, et al. Differential effects of fibromodulin deficiency on mouse mandibular bones and teeth: A micro-CT time course study. Cells Tissues Organs 2011;194: 205-10.

13. Hall R, Embery G, Lloyd D. Immunochemical localization of the small leucine-rich proteoglycan lumican in human predentine and dentine. Arch Oral Biol 1997;42:783-6.

14. Raouf A, Ganss B, McMahon C, Vary C, Roughley P, Seth A. Lumican is a major proteoglycan component of the bone matrix. Matrix Biol 2002;21:361-7.

15. Piesco NP, Avery JK. Development of teeth. In: Avery JK, editor. Oral development and histology. 3rd ed. New York: Thieme; 2002; p. 72-107.

16. Jiang B, Yokohama-Tamaki T, Wang Z, Obara N, Shibata S. Expression, localisation and synthesis of versican by the enamel organ of developing mouse molar tooth germ: An in vivo and in vitro study. Arch Oral Biol 2010;55:995-1006.

17. Ida-Yonemochi H, Ohshiro K, Swelam W, Metwaly H, Saku T. Perlecan, a basement membrane-type heparan sulfate proteoglycan, in the enamel organ: Its intraepithelial localization in the stellate reticulum. J Histochem Cytochem 2005;53:763-72.

18. Kero D, Bilandzija TS, Arapovic LL, Vukojevic K, SaragaBabic M. Syndecans and enzymes involved in heparan sulfate biosynthesis and degradation are differentially expressed during human odontogenesis. Front Physiol 2018;9:732.

19. Orsini G, Ruggeri A, Mazzoni A, Papa V, Mazzotti G, Di Lenarda R, et al. Immunohistochemical Identification of Decorin and Biglycan in Human Dentin: A correlative field emission scanning electron microscopy/transmission electron microscopy study. Calcif Tissue Int 2007;8:39-45.

20. Nahás-Scocate A, de Moraes G, Nader H, Vicente C, Toma L. Analysis of proteoglycan expression in human dental pulp. Arch Oral Biol 2018;90:67-73.

21. Tenório D, Santos M, Zorn T. Distribution of biglycan and decorin in rat dental tissue. Braz J Med Biol Res 2003;36: 1061-5.

22. Moriguchi M, Yamada M, Yanagisawa T. Immunocytochemistry of keratan sulfate proteoglycan and dermatan sulfate proteoglycan in porcine tooth-germ dentin. Anat Sci Int 2004; $79: 145-51$.

23. Nikdin H, Olsson M, Hultenby K, Sugars R. Osteoadherin accumulates in the predentin towards the mineralization front in the developing tooth. PLoS One 2012;7:e31525.

24. Listik, E, Gaschler JAM, Matias M, Feres MFN, Toma L, Nahás-Scocate ACR. Proteoglycans and dental biology: the first review. Carbohydr Polym 2019;225:115199.

25. Goldberg M, Septier D, Rapoport O, Iozzo R, Young M, Ameye L. Targeted disruption of two small leucine-rich proteoglycans, Biglycan and decorin, excerpts divergent effects on enamel and dentin formation. Calcified Tissue Int 2005;77:297-310.

26. Matheson S, Larjava H, Hakkinen L. Distinctive localization and function for lumican, fibromodulin and decorin to regulate collagen fibril organization in periodontal tissues. J Periodontal Res 2005;40:312-24.

27. Takagi M, Hishikawa H, Hosokawa Y, Kagami A, Rahemtulla F. Immunohistochemical localization of glycosaminoglycans and proteoglycans in predentin and dentin of rat incisors. J Histochem Cytochem 1990;38:319-24.

28. Wilda M, Bächner D, Just W, Geerkens C, Kraus P, Vogel W, et al. A comparison of the expression pattern of five genes of the family of small leucine-rich proteoglycans during mouse development. J Bone Miner Res 2000;15:2187-96.

29. Matsuura T, Duarte W, Cheng H, Uzawa K, Yamauchi M. Differential expression of decorin and biglycan genes during mouse tooth development. Matrix Biol 2001;20:367-73.

30. Hikake T, Mori T, Iseki K, Hagino S, Zhang Y, Takagi H, et al. Comparison of expression patterns between CREB family transcription factor OASIS and proteoglycan core protein genes during murine tooth development. Anat Embryol 2003;206:373-80.

31. Shibata S, Takahashi M, Fujikawa K. Histochemical and ultrastructural study of developing gonial bone with reference to initial ossification of the malleus and reduction of meckel's cartilage in mice. Anat Rec 2019;302:1916-33.

32. Fujikawa K, Yokohama-Tamaki T, Morita T, Baba O, Qin C, Shibata S. An in situ hybridization study of perlecan, DMP1, and MEPE in developing condylar cartilage of the fetal mouse mandible and limb bud cartilage. Eur J Histochem 2015; 59:2553.

33. Morita T, Fujikawa K, Baba O, Shibata S. An in situ hybridization study of Hyaluronan synthase (Has) mRNA in developing mouse molar and incisor tooth germs. Gene Expr Patterns 2016;21:28-40.

34. Shibata S, Fukuoka H, Sato R, Abe T, Suzuki Y. An in situ hybridization study of the insulin-like growth factor system in developing condylar cartilage of the fetal mouse mandible. Eur J Histochem 2012;56:23.

35. Shibata S, Sakamoto Y, Baba O, Qin C, Murakami G, Cho B. An immunohistochemical study of matrix proteins in the craniofacial cartilage in midterm human fetuses. Eur J Histochem 2013;57:39.

36. Calvo J, Rodbard D, Katki A, Chernick S, Yanagishita M. Differentiation of 3T3-L1 preadipocytes with 3-isobutyl-1methylxanthine and dexamethasone stimulates cell-associated and soluble chondroitin 4-sulfate proteoglycans. J Biol Chem 1991;266:11237-44.

37. Järveläinen HT, Kinsella MG, Wight TN, Sandell LJ. Differential expression of small chondroitin/dermatan sulfate proteoglycans, PG-I/Biglycan and PG-II/Decorin, by vascular smooth muscle and endothelial cells in culture. J Biol Chem 1991;266:23274-81.

38. Douglas T, Heinemann S, Bierbaum S, Scharnweber D, Worch H. Fibrillogenesis of collagen types I, II, and III with small leucine-rich proteoglycans decorin and biglycan. Biomacromolecules 2006;7:2388-93.

39. Hoshi K, Kemmotsu S, Takeuchi Y, Amizuka N, Ozawa H. The primary calcification in bones follows removal of decorin and fusion of collagen fibrils. J Bone Miner Res 1999;14:273-80.

40. Boskey AL, Spevak L, Doty SB, Rosenberg L. Effects of bone 
CS-proteoglycans, DS-decorin, and DS-biglycan on hydroxyapatite formation in a gelatin gel. Calcif Tissue Int 1997;61:298305.

41. Haruyama N, Sreenath T, Suzuki S, Yao X, Wang Z, Wang Y, et al. Genetic evidence for key roles of decorin and biglycan in dentin mineralization. Matrix Biol 2009;28:129-36.

42. Zvackova I, Matalova E, Lesot H. Regulators of collagen fibrillogenesis during molar development in the mouse. Front Physiol 2017;8:554.

43. Nanci A. Structure of the oral tissues. In: Nanci A, editor. Ten Cate's oral histology. 7th ed. St. Louis: Mosby Elsevier; 2008. p. 8-15.

44. Asari A, Miyauchi S, Miyazaki K, Hamai A, Horie K, Takahashi $\mathrm{T}$, et al. Intra- and extracellular localization of hyaluronic acid and proteoglycan constituents (chondroitin sulfate, keratan sulfate, and protein core) in articular cartilage of rabbit tibia. J Histochem Cytochem 1992;40:1693-04.

45. Zimmermann DR. Versican. In: Iozzo RV, editor. Proteoglycans: Structure, biology, and molecular interactions. New York: Marcel Dekker, Inc.; 2000. p. 201-36.

46. Alhelal A, Mahdee A, Eastham J, Whitworth J, Gillespie J. Complexity of odontoblast and subodontoblast cell layers in rat incisor. RRJDS 2016;4:68-74.

47. Fitzgerald M, Chiego D, Heys D. Autoradiographic analysis of odontoblast replacement following pulp exposure in primate teeth. Arch Oral Bio 1990;35:707-15.

48. Vanio S, Jalkanen M, Vaahtokari A, Sahlberg C, Mali M, Bernfield M, Thesleff I. Expression of syndecan gene is induced early, is transient, and correlates with changes in mesenchymal cell proliferation during tooth organogenesis. Dev Biol 1991;14:322-33.

49. Minz KP, Fisher LW, Grzesik WJ, Hascall VC, Midura RJ. Chlorate-induced inhibition of tyrosine sulfation on bone sialoprotein synthesized by a rat osteoblast-like cell line (UMR 106-01 BSP). J Biol Chem 994;269:4845-952.
50. Schaefer L, and Schaefer R M. Proteoglycans: from structural compounds to signaling molecules. Cell Tissue Res 2010;339:237-46.

51. Moscatello D, Santra M, Mann D, McQuillan D, Wong A, Iozzo R. Decorin suppresses tumor cell growth by activating the epidermal growth factor receptor. J Clin Invest 1998;101:406-12.

52. Patel S, Santra M, McQuillan D, Iozzo R, Thomas A. Decorin activates the epidermal growth factor receptor and elevates cytosolic Ca2+ in A431 carcinoma cells. J Biol Chem 1998;273:3121-4.

53. Goldberg M, Septier D, Oldberg A, Young M, Ameye L. Fibromodulin-deficient mice display impaired collagen fibrillogenesis in predentin as well as altered dentin mineralization and enamel formation. J Histochem Cytochem 2006;54:525-37.

54. Kalamajski S, Oldberg $\AA$. The role of small leucine-rich proteoglycans in collagen fibrillogenesis. Matrix Biol 2010; 29:248-53

55. Zhang G, Young BB, Ezura Y, Favata M, Soslowsky LJ, Chakravarti $\mathrm{S}$, et al. Development of tendon structure and function: Regulation of collagen fibrillogenesis. J Musculoskelet Neuronal Interact 2005;5:5-21.

56. Corsi A, Xu T, Chen X, Boyde A, Liang J, Mankani M, et al. Phenotypic effects of biglycan deficiency are linked to collagen fibril abnormalities, are synergized by decorin deficiency, and mimic Ehlers-Danlos-like changes in bone and other connective tissues. J Bone Miner Res 2002;17:1180-9.

57. Svensson L, Aszódi A, Reinholt F, Fässler R, Heinegård D, Oldberg Å. Fibromodulin-null mice have abnormal collagen fibrils, tissue organization, and altered lumican deposition in tendon. J Biol Chem 1999;274:9636-47.

58. Ameye L, Aria D, Jepsen K, Oldberg A, Xu T, Young M. Abnormal collagen fibrils in tendons of biglycan/fibromodulin-deficient mice lead to gait impairment, ectopic ossification, and osteoarthritis. FASEB J 2002;16:673-80.

Received for publication: 2 December 2019. Accepted for publication: 31 January 2020.

This work is licensed under a Creative Commons Attribution-NonCommercial 4.0 International License (CC BY-NC 4.0).

(C) Copyright: the Author(s), 2020

Licensee PAGEPress, Italy

European Journal of Histochemistry 2020; 64:3092

doi:10.4081/ejh.2020.3092 